\title{
LAS RELACIONES COMERCIALES ENTRE VENEZUELA Y ALEMANIA EN EL PERÍODO DE ENTRE GUERRAS ${ }^{(*)}$
}

\author{
ECONOMIC RELATIONS BETWEEN VENEZUELA AND GERMANY \\ IN THE INTERWAR PERIOD
}

\author{
Catalina Banko ${ }^{(* *)}$ \\ Universidad Central de Venezuela, Caracas (DF), Venezuela
}

Resumen: A partir de 1821 llegan a Venezuela numerosos comerciantes alemanes que en breve tiempo logran controlar el comercio del café en los principales puertos. Durante las primeras décadas del siglo XX, las firmas alemanas continúan desempeñando un destacado rol, incluso a pesar de las turbulencias políticas y las crisis económicas mundiales. En el presente artículo se analiza la evolución de las relaciones comerciales entre Venezuela y Alemania desde la primera posguerra, pasando por las vicisitudes de la crisis mundial de 1929 y los años de la "gran depresión" hasta llegar al estallido de la Segunda Guerra Mundial.

Palabras clave: Venezuela; Alemania; Comercio; Entreguerras.

Abstract: Since 1821, many German merchants arrive in Venezuela reaching in a short time control of the coffee trade at major ports. During the first decades of the twentieth century, German firms continue to play a prominent role, even though political turmoil and global economic crisis. We analyze in this article the development of trade relations between Venezuela and Germany since the First World War, going through the facts of the global crisis of 1929 and the years of the Great Depression until the outbreak of the Second World War.

Keywords: Venezuela; Germany; Trade; Interwar period.

(*) La presente investigación ha sido patrocinada por el Consejo de Desarrollo Científico y Humanístico de la Universidad Central de Venezuela.

${ }^{* *}$ ) Doctora, Profesora de la Escuela de Economía, de la Maestría en Historia de América Contemporánea y del Doctorado en Economía de la Universidad Central de Venezuela; Directora del Instituto de Investigaciones Económicas y Sociales "Rodolfo Quintero" (FaCES/UCV) (2011-2014). E-mail: <catalinabanko@gmail.com>. Recebido en: 07.04.2014, aceptado en: 06.05.2014. 


\section{INTRODUCCIÓN}

Tras el triunfo de la causa republicana en 1821 y la consiguiente desaparición de las restricciones para el intercambio, se abren en Venezuela nuevos horizontes para el comercio exterior que se va estructurando en torno a un nutrido grupo de compañías integradas por alemanes, ingleses, franceses, estadounidenses, italianos, holandeses y daneses. En este contexto, La Guaira y Caracas pasan a ser los principales focos de atracción para los negociantes procedentes del exterior. Una tendencia similar se manifiesta en Puerto Cabello, Maracaibo, Carúpano, Cumaná y Coro, aunque el número de inmigrantes es más reducido.

En breve tiempo comienza a observarse el creciente predominio de las firmas de origen alemán que logran consolidar sus posiciones y controlar el tráfico no solamente con Hamburgo y Bremen sino también con puertos de Inglaterra. La situación se torna particularmente favorable para el comercio a partir de la década de los sesenta gracias al incremento de la demanda mundial que motiva el ensanche de los cultivos de café en la región andina, fruto que es transportado hacia Maracaibo y luego despachado en dirección a los mercados exteriores. Este tráfico es inmediatamente dominado por los alemanes que se distinguen por su habilidad para cubrir esa vasta red de comercialización que se extiende hasta la región andina y el departamento Santander de Colombia.

Las compañías alemanas, si bien continúan conservando un papel importante en las primeras décadas del siglo XX, se ven hondamente afectadas por las contingencias de la política y la economía internacional, de manera especial como consecuencia de las vicisitudes de la Primera Guerra Mundial. Después de un proceso de recuperación en la década de los veinte, sobrevienen las secuelas de la crisis mundial de 1929. En tales circunstancias, las exportaciones venezolanas hacia Hamburgo sufren un severo impacto tanto a causa de tales desajustes como también por la orientación de la política económica de Alemania y sus planes de reactivación económica y rearme. El agotamiento de la economía agroexportadora en Venezuela y la coyuntura de la Segunda Guerra Mundial se acoplan para asestar un duro golpe a las tradicionales casas comerciales.

El objetivo del presente trabajo consiste en analizar las relaciones comerciales entre Venezuela y Alemania en el período que se inicia en la primera posguerra, atraviesa las vicisitudes de la crisis mundial de 1929 y los años de la depresión hasta llegar al estallido de la Segunda Guerra Mundial y la interrupción del intercambio entre ambas naciones.

Fuentes diversas sustentan la presente investigación. Por un lado, se ha consultado abundante material en los archivos alemanes y, por otro, se exploró la documentación localizada en Venezuela, de manera particular, en el Archivo del Ministerio de Relaciones Exteriores y en publicaciones del Ministerio de Fomento.

\section{DE LA PRIMERA POSGUERRA A LA CRISIS MUNDIAL}

El siglo XX se inicia en Venezuela en medio de graves problemas económicos ocasionados por el gran endeudamiento interno y externo y la persistente crisis de las exportaciones agrícolas. Durante la presidencia de Cipriano Castro (1899-1908) surgen 
múltiples conflictos, entre los que destaca el bloqueo naval de los puertos venezolanos por Alemania, Inglaterra e Italia como medida de presión para exigir el pago de deudas pendientes. El clima de inestabilidad se va profundizando en la medida en que se multiplican las pugnas con empresas y naciones extranjeras.

En diciembre de 1908, Cipriano Castro es víctima de un golpe de Estado promovido por el vicepresidente Juan Vicente Gómez, quien comienza así un largo período dictatorial que se prolonga hasta su muerte en 1935. Desde el principio de su gestión, pone en práctica una política de apertura a las inversiones foráneas que permite consolidar el crédito venezolano en los centros financieros del extranjero gracias a la atención regular de la deuda pública. Por entonces, los negocios se desenvuelven en un ambiente más favorable en el marco del orden y de la estabilidad reinante.

La recuperación del comercio exterior venezolano, que se está manifestando desde 1910, se ve bruscamente interrumpida por el estallido de la Primera Guerra Mundial que afecta de manera directa a las antiguas casas de origen alemán, tanto por el cierre de algunos mercados europeos como por la aplicación de las "listas negras" auspiciadas por los Estados Unidos e Inglaterra, como parte de la estrategia de boicot a los intereses germanos en el continente americano (Véase Cuadro 1). Por otra parte, desde el comienzo de la década se estaban produciendo importantes modificaciones de la estructura bancaria con la instalación de varias agencias extranjeras, principalmente estadounidenses, y la consiguiente ampliación de las fuentes de financiamiento que, hasta el estallido de la guerra, habían estado dominadas por las firmas comerciales.

Después de un extraordinario aumento de la demanda en 1919, los signos de la crisis económica mundial comienzan a emerger a mediados del año 1920, como resultado de las perturbaciones derivadas del proceso de transición hacia la paz europea. Al concluir la contienda se había registrado un incremento inusitado del comercio internacional, fenómeno que respondió a la necesidad de cubrir parte de la demanda insatisfecha durante el período bélico, lo que condujo a una gran expansión de las importaciones. Los mercados, que aún no se habían recuperado de los efectos de la guerra, se saturaron rápidamente, por lo que empezó a disminuir la demanda y los negocios sufrieron una repentina paralización que ocasionó la caída de los precios de las materias primas.

En Venezuela, las exportaciones registran un extraordinario aumento en 1919 y luego una profunda caída entre 1920 y 1921 . A mediados de la década, la economía cafetalera ya se estaba restableciendo, al tiempo que las casas alemanas más afectadas por las "listas negras" estaban retomando en buena parte su tradicional predominio (ESPINOLA, 1991, p. 121-122), tal como puede observarse en Cuadro 01:

Si observamos el panorama europeo, los años de la primera posguerra son dramáticos para Alemania con la pérdida de casi el 10\% de su población, la destrucción de la flota y del aparato industrial y la elevación de la deuda a niveles alarmantes. Como agravante, se impone a aquella nación el pago de cuantiosas reparaciones a Francia como indemnización por los daños causados durante la guerra, lo que profundiza los desajustes económicos que se traducen en un fenómeno inflacionario sin precedentes (BLEICH, 1977). 
Catalina Banko - Cadernos Prolam/USP 13 (24): p. 91-108 [2014]

\begin{tabular}{|l|l|l|l|l|l|}
\hline \multicolumn{1}{|c|}{ Firmas } & \multicolumn{1}{c|}{$\mathbf{1 9 1 6}$} & \multicolumn{1}{c|}{$\mathbf{1 9 1 8}$} & \multicolumn{1}{c|}{$\mathbf{1 9 2 0}$} & \multicolumn{1}{c|}{$\mathbf{1 9 2 2}$} & \multicolumn{1}{c|}{$\mathbf{1 9 2 4}$} \\
\hline Oliva, Ríboli\& Co. & 102.100 & 108.138 & 66.467 & 100.848 & 60.820 \\
\hline Breuer, Möller\& Co. & 121.240 & 5.637 & 40.638 & 85.200 & 209.914 \\
\hline Felipe S. Toledo & 20.348 & 37.870 & 27.279 & 106.455 & 42.334 \\
\hline Van Dissel, Rode\& Co. & 57.078 & 12.596 & 26.600 & 103.845 & 71.905 \\
\hline H. L. Boulton\& Co. & 34.571 & 14.743 & 36.911 & 93.218 & 55.943 \\
\hline Blohm\& Co. & 10.305 & & 11.037 & 117.098 & 97.188 \\
\hline Fossi\& Co. & 40.417 & 69.344 & 20.900 & 52.010 & 28.174 \\
\hline
\end{tabular}

CuAdro 01

CompañIa eXPortadoras de CAfÉ POR El PUeRTo de Maracaibo 1916-1924

(SACOS DE $60 \mathrm{KG}$ )

Fuente: Ebelio Espinola

En el transcurso de esa década, la gravedad de la situación económica alemana estimula la difusión de ideas favorables a la conformación de un Estado intervencionista, considerado el mecanismo idóneo para enfrentar los desequilibrios internos y fortalecer la independencia económica nacional. Los ideólogos de la corriente radical nacionalista cuestionan los principios del liberalismo clásico y las tendencias proclives al internacionalismo económico, al que se adjudica la responsabilidad de las crisis cíclicas del capitalismo. Por el contrario, se afirma que el nacionalismo representa la mejor opción para alcanzar la autarquía económica, al reducir la dependencia del extranjero mediante la aplicación planificada de medidas aduaneras de protección y contingentamiento, cuyo objetivo central sería el restablecimiento del equilibrio económico a través del desarrollo de las actividades productivas (DENGG, 1986, p. 78-81) ${ }^{(1)}$.

La economía estadounidense, por su parte, registra una notable expansión entre 1925 y 1929, lo que permite aumentar de manera considerable sus inversiones en los países latinoamericanos. Sin embargo, en el transcurso de estos años, aparentemente prósperos, se van gestando los desequilibrios que culminarán con el estallido de la crisis en octubre de 1929.

En ese contexto, la economía venezolana ya había sufrido cambios sustanciales como consecuencia de la inversión extranjera en la explotación de hidrocarburos. Desde 1926 el petróleo se constituye en el principal rubro de exportación, desplazando al café y cacao al segundo y tercer lugar, respectivamente. Esa explotación se convierte así en el factor dominante de la economía venezolana, en tanto que de ella proviene la mayor parte de los ingresos fiscales. La industria de hidrocarburos genera un significativo aumento de la demanda interna, tanto de mercancías como de servicios, pasando a ser el agente que dinamiza, aunque en magnitudes relativas, a la economía global.

Entretanto la agricultura sigue atravesando crecientes dificultades ante los reiterados declives del comercio internacional. Los efectos del crack de la Bolsa de Valores de Nueva York en 1929, a los que se suma la sobreproducción mundial de café, son demoledores para las exportaciones venezolanas. En ese año el precio del café es de Bs. $201,80(100 \mathrm{Kg})$, baja a 114,30 en 1930 y a Bs. 57,50 en 1935. La disminución de los

(1) Importante información complementaria se encuentra en la siguiente fuente documental: Handel 24-8 Venezuela, 45460, "Deutsche Gesandschaft", Caracas, 14 de marzo y 24 de diciembre de 1927 (Bundesarchiv, Potsdam). Las fuentes indicadas han sido consultadas en el año 1996 en la sección del Bundesarchiv ubicada en Potsdam, que posteriormente fue trasladada a Berlín. 
precios del cacao se refleja en los valores que presentamos a continuación: Bs. 114,40 (100 Kg) en 1929, Bs. 93 en 1930 y una vertiginosa caída en los años posteriores hasta disminuir a Bs. 45,50 en 1935. Ante el angustiante panorama de las exportaciones se constituye en 1930 la Asociación de Cafeteros Venezolanos, integrada por agricultores y comerciantes, con la finalidad de concretar acuerdos a nivel internacional para elevar las cotizaciones del fruto (RODRÍGUEZ, 1988, p. 86-87). Varias prominentes empresas comerciales se hallan sensiblemente afectadas por la crisis. Mientras la casa Boulton se encuentra amenazada por una quiebra inminente, la famosa firma Santana queda al margen de las grandes operaciones mercantiles.

\section{LA RESPUESTA DEL "NACIONALISMO ALEMÁN" ANTE LOS EMBATES DE LA CRISIS}

La debilitada economía alemana también es fuertemente sacudida por los efectos de la crisis mundial de 1929. En ese mismo año, cuando aún no se había sentido el impacto del desastre económico, Alemania logra renegociar el pago de las reparaciones mediante el Plan Young que reduce las cuotas anuales y extiende el vencimiento de los pagos. Sin embargo, en 1931 el desastre financiero es de tal magnitud que el gobierno debe acudir a empréstitos extranjeros para restablecer la tambaleante situación económica.

En ese cuadro de profundos desajustes, la producción alemana sufre una pronunciada caída por la contracción general del consumo. Solamente una tercera parte de las industrias se encuentra en actividad, lo que ocasiona un alto nivel de desempleo, a lo que se suma la disminución del caudal de divisas debido al endeudamiento externo. Es indispensable, por tanto, poner en práctica una política de saneamiento de las finanzas y de fomento de la producción, con lo cual podría aumentar el volumen de las exportaciones y proporcionar "trabajo productivo y rentable" para reducir el desempleo y reactivar el sector industrial (HIST, 1933, p.211-212).

La coyuntura es aprovechada por el partido nacionalsocialista para enarbolar la bandera del rescate de la independencia del pueblo alemán que, en opinión de los partidarios de ese movimiento, se había extraviado por el sometimiento a los dictados de las potencias extranjeras después del Tratado de Versalles. De acuerdo a estos postulados, la seguridad alimentaria sería la base fundamental para garantizar la soberanía nacional, para lo cual se requería de la ampliación del "espacio vital”, meta que no podría concretarse a corto plazo. Uno de los objetivos inmediatos consistía en alcanzar el autoabastecimiento, lo cual solamente sería posible mediante la acción del Estado dirigida al fomento de la industria pesada y de otros rubros industriales. De tal manera, podrían superarse las limitaciones impuestas por el "capital internacional", calificado por el nacionalsocialismo como el principal enemigo de la transformación económica alemana (Dengg, 1986, p. 86-89).

Uno de los lineamientos de la política alemana de los años treinta está dirigido a promover el comercio en Latinoamérica, para lo cual cuenta con numerosas representaciones consulares (FLOTO, 1991, p. 26-28). En el plano comercial, las naciones del continente exportan materias primas que no se producen en Alemania y, por consiguiente, la extensión de dichos vínculos económicos es de gran importancia para el desarrollo 
industrial germano. Al respecto se señala: "Alemania tendrá que importar siempre del Extranjero las primeras materias industriales de que carece, y jamás ni nunca producirá los artículos que necesita para suplir los de aquellos países, como café, cacao, frutas y tabaco" (GRÄVELL, 1933, p. 187-188).

En Alemania se reaviva el interés por estrechar las relaciones económicas con Venezuela, e incluso fomentar la inmigración hacia este territorio. Un factor fundamental reside en la paz que impera en el país bajo el férreo control del régimen gomecista. En la prensa alemana se asegura que Venezuela es una especie de "oasis" en América, por cuanto no existen campañas contrarias al nacionalsocialismo. Como muestra de esta amistosa disposición se citan los homenajes llevados a cabo en Hamburgo, Bremen y Berlín con motivo del 150 aniversario del nacimiento de Simón Bolívar (FLOTO, 1991, p. 41-45).

A mediados de 1934, Alemania envía una delegación a Sudamérica, encabezada por el ministro plenipotenciario Otto Kiep, quien en un lapso de siete meses efectúa una gira por diversos países del continente con la finalidad de intensificar las relaciones económicas. La misión se hace presente en Venezuela en enero de 1935, logrando establecer varios acuerdos comerciales y financieros para garantizar el suministro de materias primas esenciales para Alemania (FLOTO, 1991, p. 66-68).

Mientras se acentúa el interés por fortalecer los lazos con países latinoamericanos, en los medios gubernamentales de Alemania se suscitan diversas discusiones en torno a la nueva orientación económica. Una de las propuestas para superar las dificultades económicas es la devaluación del marco para aumentar la capacidad de competencia de los productos alemanes en el mercado mundial. Pero esta posibilidad es rechazada para no afectar la credibilidad de la economía germana en el mundo, no elevar el monto de la deuda externa y evitar efectos inflacionarios. En tales circunstancias se emprende el diseño de un plan para el reordenamiento del comercio exterior con el propósito de reducir al mínimo la salida de divisas por concepto de importaciones y, al mismo tiempo, incrementar las exportaciones.

\section{LA NUEVA POLÍTICA COMERCIAL ALEMANA}

Tras la consideración de diversos proyectos, triunfa en noviembre de 1934 el Nuevo Plan diseñado por Hjalmar Schacht, cuya meta consiste en instaurar medidas para adquirir materias primas esenciales para el desenvolvimiento industrial y agrícola, e incrementar paralelamente las exportaciones, lo cual además serviría de estímulo a las actividades productivas internas, y sería el medio idóneo para obtener divisas destinadas al pago de las importaciones indispensables y cubrir los compromisos de la deuda externa (SMITH, 1936).

Para poner en práctica la nueva política comercial es creada una "cuenta especial de extranjeros para pagos internos”, denominada ASKI (Ausländer sonderkonten für Inlandszahlungen). Los marcos acumulados en esa cuenta serían utilizados para cubrir las exportaciones e importaciones que, por su carácter e importancia para la economía alemana, exigían una atención particular. En el caso de que un comprador alemán deseara 
adquirir mercancías en el exterior y efectuara un convenio con un determinado comerciante extranjero, éste recibiría en la respectiva cuenta el pago mediante una moneda denominada Sondermark, en vez de los marcos utilizados en la circulación corriente. A su vez, dicha moneda solamente estaba destinada a la adquisición de productos alemanes, por lo cual un comerciante extranjero podía emplearlos directamente para realizar importaciones y, en el caso de que no le interesara ninguna mercancía alemana, podía acudir a los servicios de una entidad bancaria que operara con ese tipo de "marcos especiales", con el fin de disponer de los créditos que le habían sido abiertos en un banco ubicado en Alemania (SMITH, 1936).

El sistema de comercio exterior basado en los Sondermarks e propone estimular el intercambio ofreciendo precios superiores a los del mercado mundial, con lo cual el exportador podía vender dichos marcos en su país a un tipo bajo, sin que ello le significara pérdidas (SMITH, 1936). En realidad, el resultado de este nuevo régimen comercial es una especie de "trueque", ya que la transacción consiste en un cambio de productos sin que se llegue a registrar ninguna transferencia de fondos. De tal modo, la economía alemana se ve notablemente favorecida al estimular el aumento de las exportaciones, la obtención de suministros esenciales y el desarrollo de la industria interna, sin provocar presiones sobre la demanda de divisas (GÜNTHER, 1933, p. 407-411). Naturalmente, algunas operaciones con el exterior continúan utilizando los tradicionales métodos del comercio libre, pero se trata de reducir al mínimo esta clase de negociaciones por las razones ya expuestas (FRITZSCH, 1933, p. 87).

La regulación de las importaciones establecida por el Nuevo Plan impone controles a las importaciones con el objetivo de equilibrar la economía, evitando el ingreso de mercancías no indispensables. Esta modalidad de intercambio sirve, a partir de 1934, para mitigar las dificultades de la economía alemana y obtener insumos para su industria a cambio de la venta de artículos terminados. El concepto básico que rige el plan consiste en no comprar más de lo que es posible pagar, y comprar solamente lo estrictamente necesario (DENGG, 1986, p. 411).

En Alemania, las importaciones de caucho, metales, petróleo y alimentos se incrementan sensiblemente entre 1933 y 1938. Por el contrario, el ingreso de productos finales se reduce en ese mismo periodo de 505 millones a 397 millones de marcos. De esta manera, se asegura un abastecimiento constante para las industrias, aumenta el empleo y se garantiza el aprovisionamiento de alimentos para la población (EICKE, 1939, p. 16-17). En cuanto a las exportaciones alemanas, el mayor porcentaje está integrado por productos elaborados, tales como: artículos de metal, herramientas, máquinas, productos químicos, farmacéuticos, electrotécnicos y textiles.

La nueva política comercial alemana favorece la expansión del comercio con América Latina, ya que permite a muchos países del continente surtirse de mercancías a menor precio y, además, colocar en Alemania productos de exportación que, como consecuencia de los efectos de la larga depresión de los años treinta, tenían escasa demanda mundial.

\section{CAFÉ VENEZOLANO A CAMBIO DE SONDERMARK}

Mientras la agricultura venezolana continúa sufriendo los estragos de la depresión, va en aumento la preocupación de productores y comerciantes ante las medidas de res- 
tricción a la compra de café en Alemania. Por esta razón, Eduardo Dagnino, embajador de Venezuela en Berlín, solicita información para precisar el carácter de las nuevas políticas y su incidencia sobre las compras de café y cacao. En la comunicación respectiva se destaca que el saldo de la balanza comercial entre ambos países es favorable a Alemania y que en Venezuela no existe ningún tipo de limitaciones al ingreso de mercancías alemanas (AUSWÄRTIGESAMT, 04.06.1934, BUNDESARCHIV).

Los comerciantes residentes en Venezuela quedan totalmente desconcertados con la puesta en práctica del Nuevo Plan y, más aún, cuando en 1934 es creada la moneda de compensación. Muchos negociantes temen que los alemanes puedan interesarse por el café procedente de otros países, con los cuales ya había sido acordado el nuevo sistema de pagos. Con el objetivo de facilitar las transacciones, el Banco de Venezuela propone en diciembre de 1934 un proyecto de convenio para regular el comercio con Alemania, en el que se contempla incluir el régimen de compensación de pagos con el Reichsbank de Berlín. Este compromiso facilitaría las transacciones con Sondermark, que resultaban muy complejas cuando eran efectuadas directamente por las casas comerciales. Sin embargo, aquella negociación no sigue su curso porque un grupo de comerciantes plantea otra fórmula para resolver el asunto de las compensaciones, en un momento en que el valor de los Sondermark estaba sufriendo una severa caída (HANDEL VENEZUELA, 07.12.1934, BUNDESARCHIV).

Para resguardar los intereses de las firmas mercantiles instaladas en Venezuela, entre las que destaca Blohm \& Co., surge la iniciativa de fundar la Asociación de Exportadores de Alemania, que se encargaría de colocar los Sondermark recibidos en pago por las exportaciones, tratando de evitar toda fluctuación que pudiera lesionar los intereses de agricultores y comerciantes. La dirección de la entidad estaría a cargo de un comité integrado por las siguientes compañías: Ricardo Kölster, Pablo Prosperi, G. H. Blohm, Antero García, Francisco Gómez y Gustavo Zingg (HANDEL VENEZUELA, 14.01.1935, BUNDESARCHIV).

Las condiciones para regir el comercio con Venezuela son acordadas durante la visita de la delegación presidida por Otto Kiep, en el mes de enero de 1935, negociaciones en las que también participan algunas firmas alemanas residentes en el país. Paralelamente, se sostienen conversaciones en Berlín con el secretario de Estado Bernhard Willhelm von Büllow para redefinir las bases de las relaciones bilaterales (FLOTO, 1991, p. 70-71).

A pesar de algunos problemas planteados por los exportadores en Venezuela con respecto a las transacciones con Sondermark, se observa una tendencia ascendente de las ventas de café venezolano a partir de 1935. Al respecto debemos subrayar que Alemania constituye el principal mercado para el café tipo fino de Caracas, con excelentes cotizaciones en el mercado germano. Las casas de dicho origen más reconocidas, Blohm \& Co., G. Zingg, Van Dissel, Rode\& Co. y Breuer, Möller\& Co. Sucs., hacen también esfuerzos para lograr el incremento de las exportaciones del fruto. En cuanto a las importaciones desde Alemania, se eleva en ese tiempo la compra de tubos de acero, artículos de hierro, vidrio y cobre, productos farmacéuticos, electrotécnicos y textiles. 


\section{LA EXPORTACIÓN DE CAFÉ CONDICIONADA A LA VENTA DE PETRÓLEO}

La aplicación del nuevo plan económico alemán requiere de grandes volúmenes de petróleo para alimentar las industrias en crecimiento. En 1936 empieza a exteriorizarse el interés por adquirir petróleo venezolano, particularmente el extraído en Las Piedras por The Venezuelan Gulf Oil Comp. Las operaciones destinadas a financiar las compras de crudo estarían a cargo de un consorcio integrado por G. H. \& F. L. Blohm (Hamburgo-Caracas), Van Dissel, Rode \& Co. Sucs. y el Deutsche-Südamerikanische Bank, representados por H. J. Blohm, Hermann Meywald y Hans Wedekind, respectivamente(ALE MANIA,29.10.1936 AHMRE).

Estas negociaciones tropiezan con obstáculos difíciles de superar porque Alemania también pretende pagar las compras de petróleo con moneda de compensación, que en este caso recibiría la denominación de Ölmark (marco petróleo). El monto de la oferta alcanza a dos millones de Ölmark, para ser repartidos entre los exportadores de café a Alemania, que estarían obligados a aceptarlos y venderlos en el mercado venezolano, "so pena de no poder exportar café a Alemania”. La casa encargada de distribuir los Ölmark entre los exportadores sería P. Prosperi \& Co. Dicha moneda serviría exclusivamente para adquirir aquellas mercancías determinadas por el gobierno alemán y no para la generalidad de las manufacturas (ALEMANIA, 30.05.1936, AHMRE).

En esta operación, además de lograr suministros de petróleo sin gastar divisas, el gobierno alemán pretende obligar a las firmas exportadoras de Venezuela a recibir los Ölmark como requisito para la venta de café. Venezuela se encontraba así sometida a inauditas presiones en las que hasta el petróleo sería pagado con moneda de compensación. Como agravante, los Ölmark debían ser aceptados previamente por las casas comerciales para tener derecho a su vez a efectuar sus respectivas ventas de café.

La Cámara de Comercio de Caracas, presidida por J. M. Herrera Mendoza, reacciona contra tal iniciativa, manifestando en nota dirigida al ministro de Relaciones Exteriores Esteban Gil Borges que, según el sistema de compensaciones establecido por Alemania para las importaciones, solamente podían exportar café aquellas firmas que adquirieran Ölmark en las cantidades que se les hubiera asignado. Agrega Herrera Mendoza que en esta negociación aparecía una vez más la "antinomia existente entre los productos enteramente venezolanos y el petróleo”. Este último producto estaría compitiendo con el café y habría de introducir al congestionado mercado de Sondermark un caudal de moneda artificial que no podría ser absorbida sino con perjuicio de la exportación agrícola, al tiempo que se acentuaría la escasez de divisas extranjeras (Alemania, 30.05.1936, AHMRE).

Alfredo Olavarría, cónsul de Venezuela en Hamburgo, reitera el carácter negativo de esta operación para la agricultura de nuestro país. El diplomático afirma que los representantes alemanes habían argumentado que los tenedores de Sondermark, dispuestos a la "aceptación del marco petróleo tendrían las preferencias en los permisos para la importación de café; mientras que los dueños de ASKIS renuentes” no encontrarían facilidades para sus colocaciones de café (ALEMANIA, 26.06.1936, AHMRE).

Hans Wedekind y H. Meywald, representantes del Deutsche-Südamerikanische Bank, inician en Venezuela una serie de discusiones que derivan en un engorroso pro- 
ceso de ofertas y contraofertas. La primera propuesta alemana consiste en la compra de una tonelada de petróleo por cada saco de café, lo que significaría un total de 200.000 toneladas de petróleo y 200.000 sacos de café. Los funcionarios germanos alegan que este arreglo implica un "gran beneficio" para Venezuela, al tiempo que Alemania puede obtener el petróleo que requiere para sus actividades económicas. Los Sondermark serían abonados en una cuenta del Deutsche-Südamerikanische Bank y esa moneda serviría para pagar importaciones (ALEMANIA, 09.12.1936, AHMRE).

Néstor Luis Pérez, ministro de Fomento, responde a los representantes alemanes, Wedekind, Blohm y Meywald, que Venezuela está muy interesada en mantener buenas relaciones comerciales con Alemania, pero que lamentablemente aquella propuesta no es considerada conveniente. El gobierno venezolano sugiere una base de 150.000 sacos de café, del tipo fino de Caracas, a un precio no inferior a 50-55 Sondermark cada uno. A partir de esa oferta, se realizarían las negociaciones para la venta del petróleo que sería pagado en moneda de compensacióny en la proporción de un saco de café por cada tonelada y media de petróleo. En consecuencia, el aumento de las exportaciones de mercancías desde Alemania y la posibilidad de recibir más petróleo dependería de sus compras de café. Por el momento, el gobierno no podía hacerse cargo de las ventas directas de petróleo, pero más adelante ello sería factible en el caso de recibir el pago de las regalías en especie y no en dinero como ocurría hasta la fecha (ALEMANIA, 20.01.1937, AHMRE).

Las negociaciones se interrumpen finalmente porque las concesionarias extranjeras no aceptaron el contrato de venta del crudo, aparentemente a causa de razones políticas. Por ello, los representantes alemanes sugieren la alternativa de emprender gestiones "para llegar a la producción de petróleo mediante un acuerdo y un trabajo conjunto de los intereses germano-venezolanos". El objetivo es conseguir concesiones para emprender la explotación petrolera. Sin embargo, se trata de un proyecto a mediano plazo y, por el momento, solamente es factible esperar que el gobierno reciba sus regalías en especie y efectúe las ventas directamente a aquella nación (ALEMANIA, 27.02.1937).

Como consecuencia del fracaso de la transacción y de la búsqueda, por parte de Alemania, de otros mecanismos para obtener divisas, los representantes de esa nación formulan una nueva propuesta que es aún más inconveniente para nuestro país, ya que consiste en solicitar al gobierno venezolano el cambio de 6.550.000 de Sondermarkpor 2.000.000 de dólares, con la condición de importar 200.000 sacos de café. Las autoridades de Venezuela rechazan la petición porque se trataría de una operación propia de una oficina de cambio, destinada a satisfacer las necesidades de divisas de la economía alemana, las cuales serían utilizadas para pagar el petróleo adquirido en otros países (ALEMANIA, 05.03.1937, AHMRE).

Tras estos desacuerdos, el interés alemán por el café venezolano comienza a declinar, tal como era de prever. Por otra parte, los alemanes prefieren adquirir café más barato y de inferior calidad, otorgando prioridad al volumen de las importaciones. Ello significa una considerable baja de las exportaciones de café, a pesar de que prosiguen las compras de grandes volúmenes de mercancías a Alemania. La reducción de importaciones de café es interpretada como una represalia contra Venezuela porque no se había aprobado la venta de petróleo bajo las condiciones exigidas pordicho país (Alemania, 20.04.1937, AHMRE). 
A causa de los desajustes cambiarios que surgen en 1937, el gobierno venezolano decide crear la Oficina Nacional de Centralización de Cambios para unificar las políticas relativas a la angustiante escasez de divisas en el mercado interno, a lo que se suma la difícil situación creada con la conversión de los Sondermark obtenidos a cambio de las exportaciones hacia Alemania.

\section{EL ACUERDO COMERCIAL DE 1938}

A raíz de los desentendimientos que se habían suscitado entre Venezuela y Alemania en torno a un posible arreglo para la exportación de café, el gobierno presidido por Eleazar López Contreras opta por revisar el tratado de comercio que ambos países habían suscrito en 1909. Dentro de esa nueva tónica de la política exterior de Venezuela, el diplomático alemán Franz von Tattenbach es sorprendido en mayo de 1937 con la propuesta de modificar dicho acuerdo. Esta solicitud se fundamentaba en el hecho de que Alemania estaba aplicando controles de importaciones y efectuando pagos mediante una moneda de compensación que anulaba el principio de la nación más favorecida que estaba contemplado en el convenio vigente. En un primer momento, Alemania ofrece resistencia a esta modificación, pero poco después se difunde la noticia de que Venezuela había suscrito un acuerdo con Francia que incluía la cláusula de la nación más favorecida (FLOTO, 1991, p. 87).

El nuevo embajador alemán en Venezuela, Erwin Poensgen, protesta ante la Cancillería argumentando la violación del tratado suscrito en 1909. Pero la respuesta oficial es contundente: Alemania había dejado de cumplir con lo establecido por dicho tratado desde el momento que inició su política de control de importaciones y divisas (FLOTO, 1991, p. 88).

En el transcurso del año 1937 continúan las conversaciones para suscribir un nuevo acuerdo comercial, proceso en el que tiene activa participación el embajador venezolano en Alemania, Gustavo Herrera. La tesis venezolana apunta a las restricciones del comercio internacional y a la adopción de sistemas de licencias y contingentamientos de las importaciones por parte de Alemania, todo lo cual afecta los derechos garantizados por la cláusula de la nación más favorecida y la convierten en "enteramente ilusoria" (MINISTERIO RELACIONES EXTERIORES, 1937, p. 357).

El Ministerio de Relaciones Exteriores expresa que las medidas aplicadas por Alemania representan "retroceso en vez de desarrollo continuo y discriminación en vez de igualdad". Por tanto, los países que han abandonado unilateralmente dicha cláusula no pueden "en derecho ni en equidad invocar el tratamiento especial garantizado" en los respectivos tratados. Las críticas a tales procedimientos son enérgicas: mientras Venezuela permanece bajo un régimen de "economía liberal", la economía alemana presenta multitud de restricciones y barreras que revelan la existencia de dos sistemas "radicalmente incompatibles” (MINISTERIO RELACIONES EXTERIORES, 1937, p. 358).

La respuesta del despacho de Relaciones Exteriores en Berlín está plasmada en un documento de tono poco amistoso, a nuestro criterio. Se señala que Venezuela había recibido tratamiento de "preferencia" que se reflejaba en el notable aumento de las im- 
portaciones de café. Se recuerda también que las mercancías suministradas por Alemania a Venezuela habían sido "vendidas en su mayor parte a las compañías petroleras" y, por consiguiente, el pago fue efectuado "por un tercer país y no por Venezuela". Por ello, si se descuenta el total de las importaciones registradas en las estadísticas venezolanas, equivalente a Bs. 31.800.000, la cantidad de Bs. 7.000 .000 que es el valor de las compras realizadas por las compañías de petróleo, se podría deducir que los pagos efectivos hechos por Venezuela alcanzan solamente a Bs. 24.800.000. Además, se afirma que Alemania recibe fundamentalmente café, que es un artículo de lujo, mientras que Venezuela obtiene mercancías "necesarias para la existencia" y que, en su mayor parte, contienen materias primas que Alemania está "obligada a comprar al exterior mediante pago de divisas” (MINISTERIO RELACIONES EXTERIORES, 1937, p. 359-360).

La respuesta oficial del gobierno venezolano no se hace esperar. Se argumenta que los señalamientos sobre las exportaciones de petróleo se limitan a observar las apariencias del problema y no el fondo, ya que en verdad el objeto de la comercialización es una materia prima "integramente del suelo venezolano" y que, por tanto, se trata de importaciones procedentes de nuestro país. En consecuencia, sería necesario estudiar con calma los asuntos de interés común a ambas naciones, con un "superior criterio de justicia, de equidad, de mutua conveniencia y de durable armonía de los intereses económicos de Venezuela y Alemania"(MINISTERIO RELACIONES EXTERIORES, 1937, p. 363).

A pesar de la conducta intransigente de los representantes alemanes, la posición firme del gobierno venezolano contribuye a moderar la posición germana. En este ambiente se reanudan las discusiones, hasta que finalmente el primero de noviembre de 1938 es firmada la modificación al tratado de 1909 en los siguientes términos: En el artículo primero del acuerdo comercial se estipula que ambos gobiernos reconocen como principio regulador del intercambio el "equilibrio entre las respectivas importaciones y exportaciones". Alemania se compromete, según lo indicado en el artículo segundo, a autorizar la importación anual de una cantidad no menor de 18.000.000 de kilogramos de café y 3.500.000 kilogramos de cacao. En el artículo cuarto, que resulta ser el más debatido, se estipula que el gobierno venezolano admitirá el pago de las exportaciones en Sondermark a través de la Oficina Nacional de Centralización de Cambios. En el caso de surgir desequilibrios entre las exportaciones venezolanas y las alemanas, las partes contratantes acordarían la adopción de medidas destinadas a restablecer el normal funcionamiento del comercio. Si no se llegara a ningún entendimiento, cada una de las partes tendría el derecho de denunciar el acuerdo dando aviso a la otra con treinta días de anticipación (MINISTERIO DE RELACIONES EXTERIORES, 1938, p. 280-281).

En el curso de las negociaciones se resuelve eliminar una cláusula, introducida en la versión alemana, por la cual Venezuela debía permitir, sin limitación alguna, la salida de divisas al exterior para efectuar la liquidación de las obligaciones de los compradores de mercancías alemanas. Este punto, que se había transformado en el principal obstáculo para la firma del convenio, es finalmente excluido de los términos del tratado (ALEMANIA, 10.11.1938, AHMRE).

El convenio se convierte en un éxito para la diplomacia venezolana y para las relaciones comerciales. El tratado tendría vigencia a partir del primero de diciembre de 
1938. Sin embargo, las repercusiones positivas del convenio se ven bien pronto opacadas por las prácticas desleales de algunos comerciantes alemanes y por el estallido de la Segunda Guerra Mundial.

\section{NUEVAS DIFICULTADES PARA LAS EXPORTACIONES VENEZOLANAS}

Preocupantes son las informaciones procedentes de Alemania, ya que Schacht, el autor del exitoso plan económico, es sustituido en 1939 en sus funciones como presidente del Reichsbank por Walter Funk, quien ocupa simultáneamente el cargo de ministro de Economía, con la intención de dar unidad al rumbo de la economía. Se interpreta este cambio como una victoria de los "elementos nazis, partidarios de una política económica extremista y que está llamada a tener serias repercusiones en Europa”. En opinión de Marcel Pays, articulista del periódico parisino Excelsior, Schacht representa una línea moderada, más cercana a la ortodoxia monetaria, además de disfrutar de gran prestigio en el extranjero. Con el nuevo ministro de Economía, considerado un "agente ejecutivo del mariscal Goering, el partido toma posesión del organismo que controla los capitales y la política de emisión". Se teme que todos estos signos estén señalando la intensificación de la "economía belicosa del Reich", con "un redoblamiento de su esfuerzo militar y una tendencia cada vez más marcada en sus dirigentes a seguir los aventureros impulsos del fascismo italiano" (PAYS, 1939).

Tampoco son buenas las noticias para los exportadores de cacao debido a presuntas operaciones de dumping. Varios comerciantes denuncian que el cacao Carenero es vendido por Alemania a otros países a precios inferiores a los pagados a los exportadores venezolanos. El negocio para los alemanes consiste en comprar con Sondermark el producto venezolano y luego venderlo a precio inferior en Europa a cambio de divisas. De esta manera, el dumping practicado por los alemanes significa la pérdida de mercados para el cacao venezolano, ya que a los compradores les resulta más conveniente adquirir el producto a bajo precio en Hamburgo. Esta denuncia es realizada por la casa Boulton de Puerto Cabello y por M. Prosperi de París, preocupados ante ese tipo de especulaciones comerciales (ALEMANIA, 06.03.1939 y 23.03.1939, AHMRE). Al respecto se posee información sobre las ofertas de cacao de origen venezolano en Génova y en Dinamarca, a un precio inferior al que se había vendido a los alemanes. Estas acciones que violan el tratado venezolano-germano son reprobadas por el gobierno alemán, aunque la posición oficial no es impedimento para que se continúen efectuando operaciones comerciales en perjuicio de las exportaciones venezolanas hacia otros mercados europeos (ALEMANIA, 23.08.1939, AHMRE).

A mediados de 1939 se comienza a evaluar la conveniencia de buscar otros mercados para el café y el cacao, debido a los obstáculos interpuestos en el intercambio comercial, además de las ya señaladas prácticas de dumping en perjuicio de los productos venezolanos (ALEMANIA, 24.05.1939, AHMRE).

Al analizar la evolución de las exportaciones venezolanas, se observa un considerable aumento de las ventas de cacao a Alemania. De la exigua cifra de Bs. 356.621 por exportaciones de ese fruto en 1933 se verifica un notable incremento a Bs. 2.385.349 
en 1937 y a Bs. 4.774.206 en 1938. En 1939, estando ya en vigencia el nuevo acuerdo comercial entre ambos países, las exportaciones de cacao alcanzan en el primer semestre de ese año el monto de Bs. 3.788.357, tráfico que luego se interrumpe por el inicio de la contienda mundial (MINISTERIO DE FOMENTO, 1933-1939).

En lo referente a la composición de las importaciones venezolanas, según se desprende de algunas estadísticas publicadas en Hamburgo, la situación es la siguiente: en primer lugar se encuentra la compra de maquinarias, artículos de hierro, cemento, arroz y maíz, y en menor proporción artículos textiles y bebidas alcohólicas (HANDELUND SCHIFFAHRT, 1931).

Si hacemos un balance global del comercio entre Venezuela y Alemania en la primera mitad del siglo XX, se observan con nitidez los efectos de las fluctuaciones económicas mundiales. En 1913, el valor de las exportaciones es de Bs. 28.827.814, registrándose un notable descenso en los años posteriores. En 1926, las exportaciones son apenas de Bs. 20.685.151, aumentando a Bs. 32.378.029 en 1927 y a Bs. 36.335.393 en 1929, gracias a la reactivación de la economía alemana. Los efectos de la crisis mundial y de la depresión se expresan en una acentuada disminución de las exportaciones que llegan a su punto más bajo en 1934, con Bs. 8.754.663, incrementándose en los años posteriores hasta alcanzar Bs. 21.163.721 en 1937 y Bs. 28.378.321 en 1938, valores que siguen siendo inferiores a los años previos a la crisis mundial (MINISTERIO DE FOMENTO, 1933-1939).

Las importaciones desde Alemania registran también notorias fluctuaciones. Por ejemplo, entre 1910 y 1913 los saldos son favorables para Venezuela. Sin embargo, a partir de 1923 los balances comienzan a arrojar saldos ampliamente positivos para Alemania, a excepción de 1927 cuando las importaciones y exportaciones quedan prácticamente equiparadas. Entre 1913 y 1926, las importaciones provenientes de Alemania se elevan en 284\%. Después de una acentuada baja en los años de la depresión, las importaciones recuperan su ritmo ascendente. Entre 1935 y 1936, el aumento de las importaciones es de 68\% (MINISTERIO DE FOMENTO, 1933-1939).

Al estallar la Segunda Guerra Mundial se producen perturbaciones en la economía venezolana. La balanza de pagos se ve afectada en un primer momento por la disminución de la producción petrolera y por la caída de los precios de exportación de los productos agrícolas. La situación de este último renglón se agrava por la contracción de la demanda europea y la interrupción del comercio con Alemania, una de las principales naciones compradoras de café venezolano.

Tales circunstancias generan un severo impacto en las casas comerciales germanas, especialmente las más vinculadas con el mercado de su país de origen. Este es el caso de Van Dissel, Rode y de Breuer Möller, cuyas exportaciones caen abruptamente desde el inicio de la contienda. Distinta es la situación de Zingg y Blohm por sus conexiones con el mercado estadounidense. A partir del 17 de julio de 1941, todas las firmas germanas quedan sometidas a las restricciones de las "listas negras" elaboradas por los Estados Unidos. Esas listas se amplían en el transcurso de los años posteriores provocando prácticamente la ruina de las casas alemanas (ESPINOLA, 1991, p. 255-258). 


\begin{tabular}{|l|c|c|c|c|}
\hline \multicolumn{1}{|c|}{ Firmas } & $\mathbf{1 9 3 8}$ & $\mathbf{1 9 3 9}$ & $\mathbf{1 9 4 0}$ & $\mathbf{1 9 4 1}$ \\
\hline Tito Abbo & 143.307 & 81.199 & 115.105 & 97.330 \\
\hline Gustavo Zingg & 18.486 & 37.397 & 71.041 & 73.283 \\
\hline Van Dissel, Rode & 66.957 & 56.985 & 21.287 & 22.763 \\
\hline Blohm & 53.921 & 34.539 & 34.814 & 45.716 \\
\hline BreuerMöller & 34.271 & 27.131 & 15.658 & 11.178 \\
\hline
\end{tabular}

Cuadro 02

Firmas exportadoras de CafÉ en Maracaibo 1938-1941 (sacos de 60 KG)

Fuente: Ebelio Espinola, Las actividades de Gustavo Zingg, p. 203

A las vicisitudes de la Segunda Guerra Mundial, se suma la prohibición en Venezuela de que las sociedades comerciales efectúen operaciones cambiarias, responsabilidad que queda exclusivamente a cargo de las entidades autorizadas a tal efecto, decisión que es adoptada por el Banco Central de Venezuela en 1940. De este modo, las compañías comerciales pierden las atribuciones que tuvieron desde el siglo XIX para efectuar negociaciones de tipo bancario y cambio de divisas.

En el caso de las firmas alemanas, el impacto es aún más demoledor por las restricciones comerciales impuestas por los aliados. Pocas de esas casas comerciales sobreviven en el ambiente económico de la segunda posguerra. Por un lado, la exportación tradicional va decayendo de manera irreversible y, por otro, sobrevienen las naturales dificultades del mercado alemán en los años que siguen a la conclusión de la contienda. En ese contexto, caracterizado por la declinación de la economía agroexportadora y el peso creciente de la explotación petrolera, se inscribe la irreversible crisis de las tradicionales y polifacéticas casas comerciales, al tiempo que las relaciones económicas con Alemania se modifican sustancialmente con la contracción de la producción cafetalera en Venezuela.

\section{CONCLUSIONES}

Desde el siglo XIX, las casas comerciales de origen alemán mantienen un claro predominio en la exportación de café, de manera especial en Maracaibo, demostrando su capacidad para controlar el complejo entramado que se extiende desde el puerto hacia el interior de los espacios regionales. Esa preponderancia comienza a resquebrajarse a inicios de la siguiente centuria, como resultado del conflictivo clima reinante durante la gestión de Cipriano Castro. El panorama cambia sustancialmente en el marco del orden y de la estabilidad que caracteriza el prolongado período de dominación de Juan Vicente Gómez, aun cuando el estallido de la Primera Guerra Mundial genera una profunda alteración de las relaciones comerciales a nivel internacional.

Las dificultades no desaparecen tras la conclusión de la contienda, ya que inmediatamente nuevos desajustes de la economía internacional intensifican la situación de incertidumbre. La posterior recuperación de la economía venezolana contrasta con la profunda depresión que atraviesa Alemania durante los primeros años de la década, aunque desde 1924 comienza un lento proceso de reactivación que culmina en 1929, 
cuando nuevamente se conmueven los cimientos de la economía mundial con el crack de Wall Street en 1929. A la caída de los precios de los frutos exportables se unen las medidas proteccionistas de Alemania, que provocan serias perturbaciones en las relaciones de Venezuela con el III Reich y, en consecuencia, en la vida de las casas comerciales. Por entonces, el mercado alemán tenía gran significación para las exportaciones de café, tiempo en que la agricultura todavía era en Venezuelala principal fuente de empleo para la mayor parte de la población.

Mientras el régimen gomecista había exhibido una conducta complaciente con el gobierno alemán, a partir de 1936 la diplomacia venezolana se muestra más intransigente con las políticas puestas en práctica por aquella nación, lo cual se evidencia en la discusión y revisión del Tratado de Comercio en 1938.

A finales de esa década era ya innegable que la producción agrícola en Venezuela se estaba encaminando a una crisis terminal, fenómeno que respondía no solamente a las variaciones coyunturales del comercio internacional, sino también a los problemas estructurales del sector. La escasa diversificación de la producción, el atraso técnico y la insuficiencia de vías de comunicación contribuían a la debilidad de la agricultura, todo ello agravado por las contingencias políticas y económicas del mercado mundial que obstaculizaban las inversiones y la expansión de los cultivos.

A las secuelas de la depresión y a la permanente pugnacidad con Alemania por la aplicación de políticas proteccionistas, se agregan poco después los efectos de la Segunda Guerra Mundial y la consiguiente paralización de las exportaciones hacia Europa.

En los años que siguen a la finalización del conflicto, la situación de las firmas alemanas no registra mejorías. Por un lado, las restricciones establecidas por las naciones aliadas dejan una huella profunda en la dinámica comercial y, por otro, se verifica un cambio fundamental en la base de la estructura productiva en Venezuela: la economía deja de estar sustentada en la exportación de productos agrícolas para pasar a ser cada vez más dependiente de la renta petrolera. Este proceso marca la irreversible crisis de las tradicionales casas comerciales que desde el siglo XIX habían transitado el ciclo de la Venezuela agroexportadora.

\section{BIBLIOGRAFÍA}

\subsection{LIVROS E PERIÓDICOS}

BLEICH, Fritz. Die Wirtschaftskrise 1925-1926 und die Reichsregierung. Kallmünz: Buchdruckerei Michael Lassleben, 1977.

DENGG, Sören. Deutschlands Austritt aus dem Völkerbund und Schachts Neuer Plan”. Frankfurt am Main: Verlag Peter Lang, 1986.

EICKE, Rudolf. Warum Aussenhandel? Berlin: Verlag für Sozialpolitik, Wirtschaft und Statistik Paul Schmidt, 1939.

ESPINOLA BENÍTEZ, Ebelio. Las actividades de Gustavo Zingg 1899-1946.Caracas: Tesis de Maestría, USM, 1991. 
FLOTO, Jobst-H. Die Beziehung Deutschlands zu Venezuela 1933 bis 1958. Frankfurt am Main: Peter Lang Verlag, 1991.

FRITZSCH, Rolf . Bedeutung und Aufgabe des Deutschen Aussenhandels. en Deutschland in der Wirtschaft der Welt. Berlin: Deutscher Verlag für Politik und Wirtschaft,1937.

GRÄVELL, Walter. Repercusión forzosa de la crisis alemana en Ibero-América. en Iberoamérica y Alemania. Berlín: Carl Heymanns Verlag, 1933.

GÜNTHER, Walter. Die Organisation des Deutschen Handels.En: Edgar Bissinger: Der Deutsche Handel Aufgabe und Zukunft. Berlin: s/e, 1933.

HIST, Bernard. "Posibilidades del desarrollo comercial entre Ibero-América y Alemania" en Iberoamérica y Alemania. Berlín: Carl Heymanns Verlag, 1933.

MINISTERIO DE FOMENTO, Estadística Mercantil y Marítima de Venezuela (1933-1939).

MINISTERIO DE RELACIONES EXTERIORES. Política Económica. Alemania. Aplicación de la cláusula a la nación más favorecida. En: El libro amarillo. Caracas, (1937).

MINISTERIO DE RELACIONES EXTERIORES. Acuerdo Comercial entre Venezuela y Alemania. En: El libro amarillo. Caracas, 1938.

PAYS, Marcel. Es retirado el dictador de la economía del Reich. En: Boletín de la Cámara de Comercio de Caracas. n. 303, París, enero 1939.

RODRÍGUEZ GALLAD, Irene. Perfil de la economía venezolana durante el régimen gomecista. En: Juan Vicente Gómez y su época. Caracas: Monte Ávila Editores, 1988.

SMITH, Gerald. Competencia del comercio alemán en la América Latina. En: Boletín de la Cámara de Comercio de Caracas, 1936.

\subsection{FUENTES DOCUMENTALES}

\subsubsection{ALEMANIA: BUNDESARCHIV}

AUSWÄRTIGESAMT, ABTEILUNG III, Kaffee, Venezuela, 46583, Legación de Venezuela, Berlín, 4 de junio de 1934.

HANDEL 24-8 VENEZUELA, 45460, Deutsche Gesandschaft, Caracas, 14 de marzo y 24 de diciembre de 1927.

HANDEL VENEZUELA, 45438, Vorschlag des Banco de Venezuela, Caracas, 7 de diciembre de 1934. HANDEL VENEZUELA, 45438, Asociación de Exportadores a Alemania, 14 de enero de 1935.

\subsubsection{VENEZUELA: ARCHIVO HISTÓRICO DEL MINISTERIO DE RELACIONES EXTERIORES (AHMRE)}

ALEMANIA. Dirección de Política Comercial, 1936. Exp. 10, Oel Marks (marcos petróleo) Sondermarks, E. Gil Borges a Franz von Tattenbach, Caracas, 30 de mayo de 1936.

ALEMANIA. Dirección de Política Comercial, 1936. Exp. 10, Oel Marks (marcos petróleo) Sondermarks, Alfredo Olavarría, Hamburgo, 26 de junio de1936.

ALEMANIA. Dirección de Política Comercial, 1937. Exp. 9, Hans Wedekind y H. Meywald, y el petróleo, Hans Wedekind, Caracas, 9 de diciembre de 1936.

ALEMANIA. Dirección de Política Comercial, 1937. Exp. 9, Hans Wedekind y H. Meywald, y el petróleo, Néstor Luis Pérez, Caracas, 20 de enero de 1937. 
ALEMANIA. Dirección de Política Comercial, 1937. Exp. 9, Hans Wedekind y H. Meywald, y el petróleo Wedekind y H. Meywald, Caracas, 27 de febrero de 1937.

ALEMANIA. Dirección de Política Comercial, 1937. Exp. 9, "Hans Wedekind y H. Meywald, y el petróleo" E. Gil Borges, Caracas, 5 marzo 1937.

ALEMANIA. Dirección General. 1937. Exp. 7. Sobre posibles dificultades en la importación del café venezolano, Tovar Lange, Berlín, 20 abril 1937.

ALEMANIA. Dirección de Política Comercial. 1939. Exp. 14. Sobre cacaos venezolanos, perjuicios para la exportación. Luis Monsanto, París, 6 de marzo 1939. Andrés Boulton, Puerto Cabello, 23 de marzo de 1939.

ALEMANIA. Dirección General. 1939. Exp. 9. Operaciones de dumping con café de Venezuela, Zérega Fombona, Berlín, 23 de agosto de 1939.

ALEMANIA. Dirección General. 1939. Exp. 9. Operaciones de dumping con café de Venezuela, Rafael Angarita Arvelo, Berlín, 24 de mayo de 1939. 